\title{
Psychosocial factors influencing the perception and choice of nursing as a profession: A study at Korle - Bu nurses' training college
}

\author{
Prudence Portia Mwini-Nyaledzigbor ${ }^{1}$, Samuel Atindanbila ${ }^{2}$, Gladstone F. Agbakpe ${ }^{3}$, \\ Edward Abasimi ${ }^{4}$ \\ ${ }^{1}$ School of Nursing, College of Health Sciences, University of Ghana, Legon \\ ${ }^{2}$ Department of Psychology, University of Ghana, Legon \\ ${ }^{3}$ Department of Psychology, Methodist University College Ghana, Dansoman \\ ${ }^{4}$ School of Medicine and Health Sciences, University for Development Studies, Tamale
}

\section{Email address:}

mwinituo@yahoo.com (P. P. Mwini-Nyaledzigbor), atindanbila@gmail.com (S. Atindanbila), gladstonef@yahoo.com (G. F. Agbakpe), abasimieddie@yahoo.com (E. Abasimi)

\section{To cite this article:}

Prudence Portia Mwini-Nyaledzigbor, Samuel Atindanbila, Gladstone F. Agbakpe, Edward Abasimi. Psychosocial Factors Influencing the Perception and Choice of Nursing as a Profession: A Study at Korle - Bu Nurses' Training College. Psychology and Behavioral Sciences. Vol. 3, No. 1, 2014, pp. 25-32. doi: 10.11648/j.pbs.20140301.15

\begin{abstract}
This paper explored the psychosocial factors influencing the perception and choice of nursing as a profession by student nurses. Three hundred and sixty student nurses $(\mathrm{N}=360)$ were systematically sampled from Korle - Bu Nurses' Training College in the Accra Metropolis in Ghana. A self-designed questionnaire on the students' perception of the nursing profession and the factors that influenced their choice of nursing as a career was administered to students in their first, second and third year of study in the programme. The results were analyzed using ANOVA and Chi square Test of Independence. The findings of the study revealed that the students had a favourable perception of nursing as a profession. The psychosocial factors that influenced their choice of nursing included, the opportunity that the profession will offer for them to travel abroad and influence from parents. It was recommended that the government should formulate policies to upgrade remunerations for professional nurses in the country to minimize the exodus of nurses since the study indicated that students had high levels of intention to travel abroad after graduation.
\end{abstract}

Keywords: Psychosocial Factors, Choice of Nursing, Nursing as a Profession, Korle - Bu Nurses' Training College

\section{Introduction}

The nursing profession has existed since the time of the caveman who, returning wounded from the hunt, had his sores dressed by the cavewoman. Closer to our own era, modern nursing is said to have begun with Florence Nightingale with the opening of her first school of nursing in 1860 for the purpose of service to mankind (Dolan, Fitzpatrick \& Herrmann, 2005; Bullough \& Bullough, 1993). Despite our long history of social service, the social mission of nursing today is far from clear (Corley \& Mauksch, 1993). For some, people within the profession, as well as outside it, the nurse is the physician's helper- more poetically described as the "handmaiden of the physician" (Corley \& Mauksch, 1993). For others, the nurse is an autonomous professional who also carries out medical orders (Corley \&
Mauksch, 1993). Between these two extremes the role of the nurse can be perceived and described in many different ways but Oates (2006) reported that nurses and their role has been the subject of several sociological studies.

Corley and Mauksch (1993) compared the nursing profession to a sheet of rolled-out dough from which many cookies have been cut and the cut out cookies are rising and browning independently in the oven and represent the traditional functions of the nurse that have been taken over by new groups of health workers. What is left of the sheet of dough now constitute nursing whilst much of the remaining dough has been given to others, and the battle for the new and sought-after dough has not been completely won [this is what is described as the changing role of the nurse] Corley and Mauksch (1993). It is in this way, nursing does not provide a pretty picture for the profession in Ghana. The 
situation presents an opportunity to ask ourselves individually and collectively, some very basic questions about who we are:

- Who is a nurse?

- What is good about nursing?

- What can one achieve as a nurse?

- What is it that attracts young adults into the nursing profession?

The reader may find the answers to some of the above questions whereas others may require further probing by nurses themselves.

The demand for more qualified nurses is evident in all health care settings in the world. A number of documented reasons (Larson, McGill \& Palmer, 2003) support the need for more professional nurses in any developing country such as Ghana due to the following reasons:

- An increasing maternal and infant mortality rates in Ghana

- The increased prevalence of non-communicable and chronic diseases.

- An increasing number of ageing nurses

- The need for technological and medical advances to resolve sanitation problems and eradicate infectious diseases.

- The need to increase the survival rates of individuals with acute diseases and trauma.

- The movement towards a community-based approach to health care.

These societal and demographic changes led the Ministry of Health, Ghana ([MOH], 2009) to prompt that health care services will increase in the $21^{\text {st }}$ Century amidst the boom for greener pastures abroad drawing professional nurses away. With this phenomenon occurring, Ghana is experiencing decreasing number of qualified registered nurses and took the initiative to train younger nurses $(\mathrm{MOH}$, 2009).

Therefore, in 2000 the MOH developed and implemented a continuing education programme designed to increase the countrywide training and distribution of auxiliary and professional nurses prepared to perform nursing care duties. Caring is the foundation for the practice of nursing as well as its moral imperative. Thus, the description of a highly competent practice of nursing must make explicit the relationship between advanced clinical knowledge and judgment and highly evolved caring practices. The caring relationship between a patient and the nurse is the common denominator in all stories about making a difference (Benner, Tanner, \& Chesla, 2009). However, to understand the unique and central place of caring in nursing practice is important in distinguishing between the caliber of the people to be selected and trained as nurses.

This descriptive exploratory study (Polit \& Beck, 2008) was undertaken to ascertain the views of young adults in Ghana, on the factors influencing their choice of nursing as a career. Little empirical data exists about why young Ghanaians choose to become nurses in the 21 st century. Further, little is known about their future career plans or their intentions to remain in the nursing workforce. Currently there is a global nursing workforce shortage with indications that shortages will continue into the future. The nursing shortage is occurring at a time when many populations are ageing and placing unprecedented demands on both the health care providers and the health care systems. Not only are populations ageing, the burden of chronic diseases is escalating in recent times. However, there is strong evidence highlighting positive patient outcomes when nursing care is provided by registered nurses. Therefore the long term retention of young nurses is of critical importance for both the health care consumer and the profession.

\subsection{Statement of the Problem}

The Diploma Nursing programme in Ghana is a countrywide effort that seeks to integrate a number of existing systems in an effort to address the shortage of nurses in Ghana. Health care employers, colleges and Universities have combined efforts to reach out to suitable applicants to improve recruitment, training, placement and retention of nurses. Several Nurses' Training Colleges (NTCs) have been opened in all the ten regions of Ghana, in addition to already existing ones for the training of nurses in areas such as, Registered General Nursing, Psychiatric Nursing, Community Health Nursing and Midwifery. The intended outcome is to turn out several nurses and increase the supply of nurses throughout the country.

The countrywide initiative is critical to the country's health care industry and economy. It is estimated that nurses make up $80 \%$ of the total health care employment in Ghana (Ghana Health Service [GHS], 2010), since nurses are found in many villages and hamlets wherever there is a healthcare service facility. Despite this, health care managers are experiencing a critical shortage of qualified nurses, as nurses continue to leave the shores of Ghana or via into care provision in other Non-Governmental Organizations (NGOs) after graduation from the colleges much sooner than expected (GHS, 2010). Wade and Degerhammer (1995) conducted a study on job satisfaction among nurses in Scandinavian hospitals and found that intrinsic factors have closer relationships in determining satisfaction among nurses in hospitals and included factors such as academic achievements and recognition. In Ghana, it is a lack of recognition or academic achievements for nurses or a new movement that forces nurses out to work in other developed countries and other organizations other than the ministry of health and Ghana health service (MOH/GHS) facilities while the increased demand for nurses is occurring at a time when there are also increased health care needs of our population and an increased "graying" of the nursing profession? This inspired the need for this research to explore the factors influencing the choice of nursing as a career by young adults in Ghana.

The exodus of nurses and other events put pressure on the nursing industry in Ghana and there is the need for research to identify and solve any related problems on the lack of 
retention of nurses in the country's health institutions. Adam and Bond (2000) researched on job satisfaction/dissatisfaction among nurses in Botswana and found that nurses were generally not satisfied with their job and developed obstinate attitudes towards patients and their care. Therefore, much as one would love to have more people trained as nurses, caution need to be taken in selecting the "would" be nurses to be able to meet the demands of society.

In recent years, there has been an influx of applications from young adults to enter the Nursing profession. Statistics from the Human Resource Division of the Ministry of Health (MOH, 2009) indicate that the number of applicants to nursing colleges had been showing an upward increase over the years. Records on the numbers of young adults in Ghana, applying for admission into the Nurses' Training Colleges from 2000 to 2009 alone show that over thousands of applicants were seeking admissions yearly though virtually, only half of the applicants usually get admitted.

The Table 1 depicts the number of yearly applicants seeking admission into the Nurses' Training colleges in Ghana.

Table 1. Applications from young adults

\begin{tabular}{lll}
\hline Year & Number of Applicants & Number Admitted \\
\hline 2000 & 2376 & 648 \\
2001 & 3181 & 662 \\
2002 & 5643 & 843 \\
2003 & 6505 & 1159 \\
2006 & 14000 & 9000 \\
2007 & 25000 & 10000 \\
2008 & 30000 & 10224 \\
2009 & 34000 & 11546 \\
\hline
\end{tabular}

Source: Human Resources Division, Ministry of Health, Ghana (2010)

Hardly does every applicant secure a place to be trained. Well qualified and perhaps potentially capable would be nurses are often turned away for reasons of lack of adequate infrastructure and resources in training institutions. On the contrary there exists a high demand for qualified nurses to meet the overwhelming health needs of the Ghanaian population. In order to secure admission, some applicants make attempts to falsify their Senior High School Certificate Examinations (SHSCE) results and other documents such as birth certificates to satisfy entry requirements to these training institutions. This has attracted great attention from all the country's media on matters concerning nursing enrollments. For example the Daily Graphic, March, Issue, reported how certain students of some Nurses Training Colleges allegedly used fake Certificates to seek admission and had to be arrested by the police for their dishonesty while others abandoned the course and absconded to escape being arrested.

Review of available literature demonstrates paucity of research in the area of factors influencing the choice of nursing as a career option by young adults in West Africa, in general, and in Ghana in particular. Therefore, the present research is needed to explore the perception of young people about the nursing profession in Ghana. The following questions, pave the way for the investigation of the factors influencing the choice of nursing as a profession by young adults in Ghana.

Do successful applicants who enter the Nursing Training Institutions come with some hidden agenda or motives? What are the perceptions of young people about the nursing profession as a career choice and what has accounted for the desperate need by young adults in Ghana to train as nurses?

\subsection{Objectives of the Study}

The main objective of the study was to investigate the factors that influenced the choice of Nursing as a career. To enable the researchers realize the main objective of the study specific objectives were set as follows:

1. To determine the perception of student nurses about the nursing profession.

2. To identify the role of parental influence in the choice of Nursing by their children

3. To investigate the relationship between the intention of student nurses to travel to developed countries after graduation and their choice of nursing as a profession.

\subsection{Hypotheses}

The following hypotheses have been tested:

1. There is a significant favourable perception of first year student nurses of the nursing profession than both 2nd and 3rd year student nurses.

2. There is a significant positive relationship between parental influence and choice of nursing as a professional career.

3. There is a positive correlation between student nurses intention to travel to developed countries after graduation and their choice of nursing as a career.

\subsection{Significance of the Study}

The findings of the study will contribute to the preparation of interview guidelines that will explore young adults' motives for selection of nursing as a career option and also contribute knowledge for career counselors in first and second cycle educational institutions. The results will help direct policy makers regarding retention and attrition of nurses in Ghana.

\section{Review of Relevant Literature}

In a study conducted by Kersten, Bakewell and Meyer (2003) on the motivating factors in a student's choice of nursing as a career amongst nine Bachelor of Science (BSN) and eleven Advanced Diploma in nursing schools, it was found that the most frequently reported reasons for choosing nursing were: nurturance, emotional need, employment opportunities, financial benefits and interest in science. Practicing nurses were identified most frequently as 
influencing students' image of nursing and their choice of nursing as a career. Similarly in Ghana, can it be concluded that the current attitude of Ghanaian nurses traveling to developed countries is influencing young adults' choice of the nursing profession as a career?

Nursing continues to be perceived as a caring profession as well as one that offers many personal benefits. Writing in her book "To Be a Nurse", Adam (1991) submitted that nurses collaborate in the carrying out of doctor's orders and with other health professionals in various ways and that nurses have as well, an independent social mission to accomplish. She concluded that nursing was a remarkable and worthwhile service and one that is greatly considered important by most societies (Adam, 1991).

Several nursing researchers and publications have indicated the growing numbers of applicants for nursing training institutions. According to Kenny (2002), between a third and a half of all people who applied for places for pre-registration nursing courses in the United Kingdom (U.K) are turned down because the supply of places cannot keep pace with the demand for training. Similarly, in a qualitative study among student nurses in the UK, concerning the factors influencing their choice of nursing as a career, Gibbs (2002) reported the following verbatim quotations from the participants:

"The first advantage in being a nursing student is that, your employment worries are over. The nightmare facing other undergraduates studying non-nursing in trying to get a job at the end of their courses is great.

... as a nursing student, just check out the jobs at the back of Nursing Times Journal. We are going to have little or no problems finding work and graduating straight into a $£ 16,000$ a year job. We get paid to get our qualification; we happily pull in $£ 5,000$ a year for the privilege of attaining a versatile respected qualification. There is also the issue of flexibility and ego-boost from compliments of patients (Gibbs, 2002).",

Stevens and Walker (2003) undertook a research on choosing a career. A descriptive design was used and six hundred and forty one $(n=641)$ college bound high school seniors in Washington D.C. Metropolitan area were surveyed. The findings indicated that the decision to choose or not to choose nursing was significantly influenced by demographic characteristics such as age, ethnicity and race. Past experiences with nurses and or illness were the other preferred characteristics in choosing the profession of nursing. Those respondents who chose nursing cited wanting to help people, to do important work, and to work with a variety of people as important reasons for their choice. Those who did not choose nursing indicated dislike of dying people and low salary as the main reasons for choosing other careers instead of nursing. Also, the respondents reported that they were seeking interesting, challenging and exciting work, job security, the ongoing demand for nurses, the ability to leave and return, as well as the ability to combine work and family, as some of the important factors that help them to choose to become nurses.
Furthermore, Benner, Tanner and Chesla, (2009) in writing about expertise in nursing practice, caring and making ethical clinical judgment indicated a drive by traditional values of altruism, the desire to care for others, the ability to work closely with people, as well as being able to make a strong contribution to society. Similarly, Larsen, McGill and Palmer (2003) carried out a study on factors influencing career decisions from the perspectives of nursing students, in North Carolina to describe the effects of motivating factors and characteristics of the nursing profession on students selecting nursing as a career. Students from three types of programmes $(\mathrm{N}=495)$ were asked to complete a survey questionnaire during the first month of their nursing programme. Motivation factors influencing the decision to become a nurse were past experience with a loved one or self-being ill/or hospitalized, past health care work experience and having a family member or friend who was a nurse. Characteristics about the nursing profession influencing career decision were care and concern for others, job security and variety of work setting. Neither one of the motivating factors nor characteristics of the nursing profession differed among students from each programme type.

Further more, Law and Arthur (2003) and Hawkins (2001) studied factors influencing Hong Kong and Tennessee school students in their choice of a career in nursing and found that students' decision to choose nursing or not was significantly influenced by the demographic factors such as gender, biology subject pursued, previous academic achievement and mother's occupation. The students' intention to study nursing was also significantly affected by social influence, parents, school career masters and friends; past experience with career activities, and working in a hospital.

Also, Beck (2002) studied nursing students at a large University in New England and found that an intense desire and genuine love of helping others was a predominant motive for choosing nursing as a career and prior work experiences and hands of caring for family and friend confirmed the students' inclination towards nursing. Also, exposure to family and friends in the health care profession sparked students' interest in a career choice of nursing.

In conclusion, therefore, the review of available literature demonstrates the paucity of research in the area of the factors influencing the choice of nursing as a career option by young adults in West Africa in general and in Ghana in particular. Therefore, the present research is needed to explore the perception of young people about the nursing profession in Ghana.

\section{Methodology}

\subsection{Research Setting}

Korle - Bu Nurses Training College was chosen for the study. The reason is that it is a premier school and has students from all the ten regions in Ghana and therefore the results can be generalizable to a large extend. 


\subsection{Research Design}

A quantitative exploratory survey approach (Polit \& Beck, 2008) was used to investigate the factors influencing the choice of nursing as a career and the perceptions of students about the nursing profession.

\subsection{Sample and Sampling Procedure}

Three hundred and sixty students $(\mathrm{N}=360)$ were selected for the purpose of the study. Out of 360 questionnaires distributed, only 299 were returned, giving a response rate of about $83 \%$. Out of which 118 were second year students (78.7\%), 129 students were from first year (86\%) and 52 third year students $(52 \%)$. They were selected by the use of the systematic random sampling technique. Selected subjects were then contacted during lecture hours. They were briefed about the study and then informed and consent sought. The questionnaires were given to them and they were asked to complete to and return within two days. The researchers went back for completed questionnaires after the second day.

\subsection{Instrument for Data Gathering}

A self designed questionnaire was used by the researchers as the data gathering tool. It consisted of two main sections. Section (a) elicited information on the demography of the subjects. This included age, sex, marital status, religious affiliation, educational background, and parent /guardian occupation, if any of the student prior to entering the Nurses' Training College. Section (b) concentrated on factors that influence the student to choose the nursing profession and the perception of nursing as a career.

\subsection{Pilot Study}

A pilot study using the questionnaire on students $(\mathrm{N}=10)$ at a Psychiatric Nurses' Training College in the city of Accra. This facilitated the reframing of the items on the questionnaires which were ambiguous. Those that could not be properly structured were taken out. The final questionnaires after the correction which the researchers thought were comprehensive enough in eliciting information needed to answer the research questions consisted of (21) questions in two sections $\mathrm{A}$ and $\mathrm{B}$.

\subsection{Ethical Considerations}

Letters were written to the Director of the training institution and participant information sheets were distributed to students in all classes for them to read and learn about the study and about the rights of a participant in order to obtain consent in the conduct of the study. Students were briefed about the significance of the study. All the participants signed consent forms. They were informed they could volunteer to participate or withdraw from the study at any stage on their own volition and will not be penalized. Information provided was also kept confidentially in an office of the researchers at the University of Ghana campus and was handled by only them. The information was also used strictly for research purposes.

\section{Findings}

\subsection{Nurses' Perception of the Nursing Profession}

Table 1 presents the mean and standard deviation obtained on the participants' perception of the Nursing profession.

Table1: Means, SD, ANOVA of Nurses' Perception

\begin{tabular}{cccccc}
\hline Year & Mean & $\boldsymbol{S D}$ & $\boldsymbol{d} \boldsymbol{f}$ & $\boldsymbol{F}$ & $\boldsymbol{p}$ \\
\hline 1st & 34.42 & 8.79 & 2,296 & 7.38 & .02 \\
2nd & 38.03 & 5.85 & & & \\
3rd & 35.00 & 8.14 & & & \\
\hline
\end{tabular}

From table 1 above it can be observed that there was a significant difference in the perception of nursing among the various years of training in the nursing school $F(2,296)=$ $7.38, p=.02$, one-tailed). The post hoc analysis revealed that students in the second year $(M=38.03, S D=5.85)$ had the highest positive perception of the nursing profession as compared to students in both years one and three which have similar levels of perceptions.

This contradicts the hypothetical prediction that "the first year students would have a more favorable perception of the nursing profession than both the $2^{\text {nd }}$ and $3^{\text {rd }}$ year students. This indicates that the hypothesis was not supported.

\subsection{Parental Influence on the Choice of Nursing}

The second hypothesis states that there will be a positive relationship between parental influence and the choice of the nursing profession by the participants. In view of this the Chi square test of independence was used in order to determine the association between the two categorical variables (parental influence and choice of profession). Table 2 presents the statistical results obtained on these variables.

Table 2: Chi Square Test of independence on parental influence on students' choice of nursing.

\begin{tabular}{cccccc}
\hline RESPONSE & $\boldsymbol{N}$ & $\boldsymbol{d f}$ & $\boldsymbol{X}^{2}$ & $\boldsymbol{p}$ & Phi value \\
\hline Parental influence & 221 & 1 & 69.58 & .03 & .414 \\
No parental influence & 77 & & & & \\
\hline
\end{tabular}

The results indicate that the relationship between parental influence and choice of the nursing profession among the students at Korle- Bu Nurses training college was significant $\mathrm{X}^{2}(1, N=298)=69.58, p=.03$, phi value $=.414$. The association was moderate since the square of the phi value was $=.1714$. Therefore the choice of profession accounted for $17 \%$ of the variance of parental influence. This indicates that the second hypothesis was supported. 


\subsection{Exodus of Nurses}

The last hypothesis stated that there is a positive correlation between student nurses' intention to travel to developed countries after graduation and their choice of nursing as a career. The chi square test of independence was used to determine this relationship which is shown on the table 3 below.

Table 3: Chi Square Test of independence on students' intention to travel and choice of nursing

\begin{tabular}{cccccc}
\hline RESPONSE & $\boldsymbol{N}$ & $\boldsymbol{d f}$ & $\boldsymbol{X}^{2}$ & $\boldsymbol{p}$ & Phi value \\
\hline Travel intention & 242 & 1 & 133.38 & .04 & .56 \\
No travel intention & 46 & & & & \\
\hline
\end{tabular}

The results indicate that the relationship between students at Korle- $\mathrm{Bu}$ Nurses training college intention to travel and their choice of the nursing profession was significant $\mathrm{X}^{2}(1$, $N=242)=133.38, p=.04$, phi value $=.560$. The association was moderate since the square of the phi value was $=.314$. Therefore the choice of profession accounted for $31 \%$ of the variance of intention to travel after graduation by student nurses at Korle-Bu Training College. This indicates that the third hypothesis was supported.

\section{Discussion}

This study has three main objectives. The first one seeks to determine the perception of student nurses about the nursing profession. This is followed by the second one which is to identify the role of parental influence in the choice of Nursing by their children. The last objective is to investigate the relationship between the intention of student nurses to travel to developed countries after graduation and their choice of nursing as a profession. In view of this three hypotheses were stated and tested and the following results were obtained and discussed below.

As stated above, the first objective which sought to find the perception of student nurses about the nursing profession was found to be positive. This is because the second year students had the highest level of positive perception of the profession which was followed by the first and third years.

This favourable perception exhibited by the participants in this study reflects the Ghanaian public perceptions of the nursing profession. The Ghanaian public are mostly of the opinion that the nursing profession is an area of ready job availability and paid allowances during training periods that gives relief to low income parents. Furthermore, the trainee nurses were overwhelmingly satisfied with their decision to become nurses but they were very clear about the future prospects of the profession. They also have plans to travel abroad after graduation. This finding confirms that of Kersten, Bakewell \& Meyer (2003), Larsen, McGill \& Palmer ( 2003) and Benner, Tanner, \& Chesla (2009) who found that the most frequent reported reasons for choosing nursing include love to care for others, past experience in hospital, employment opportunities and job security.
The findings of this study also confirms those of Beck (2002)' Law and Arthur (2003), Hawkins (2001), Fry and Johnstone (2008) regarding the nurses' uniform as a symbol of attraction and the benefits for the use of science learnt in school. According to these researchers, the nurses' code of ethics as stipulated by the International Council of Nursing (ICN) carries personal responsibilities and accountability for nursing practice and for maintaining competence by continual learning, not embossed in spectacled dress codes or attires.

However areas that student nurses had negative perception included strained relationships between them and other members of the health team. Research is much needed in this aspect of the roles of nursing service and healthcare service administrators in the retention of nurses in Ghana.

The second objective was aimed at identifying the role of parental influence in the choice of Nursing by their children. The analysis revealed that the relationship between parental influence and choice of the nursing profession among the students at Korle- Bu Nurses' Training College was positive. The association was moderate ( $p h i$ value $=.1714$ ). This indicates that the choice of profession accounted for $17 \%$ of the variance of parental influence.

The parental influence seems to be common where most parents take decisions for their children even at the adult age according to the Ghanaian culture.

The last hypothesis which stated that there is a positive correlation between student nurses' intention to travel to developed countries after graduation and their choice of nursing as a profession was also analyzed. The results revealed that the relationship between students at Korle- $\mathrm{Bu}$ Nurses training college intention to travel and their choice of the nursing profession was a moderately positive relationship. The choice of profession accounted for $31 \%$ of the variance of the intention to travel after graduation.

This finding is consistent with previous findings. For example a positive correlation between exodus of nurses to the developed world and choice of nursing was found by Oates (2006). The students' aspirations to travel outside for better services in the developed world are motivating the choice of nursing profession among most young Ghanaians. Oates (2006) reported similar findings in a survey among Australian and New Zealand nurses and concluded that a Registered Nurse belongs to a profession that is 'transportable' and in high demand. Once registered, nurses are eligible to register in any overseas country of their choice as the profession offers many opportunities for travel, to obtain diverse nursing experiences, and to care for people in different cultures. Being able to work and travel anywhere in Ghana and overseas is a benefit that few professions provide.

\section{Recommendations}

Based on the findings of the study, the following recommendations are made:

1. The finding that the students have a positive perception 
about the profession implies that both students and the tutors should make good use of this attitude which should be translated into practice for the patients to benefit. However areas that student nurses had negative perception which included strained relationships between them and other members of the health team needs to be improved upon by management.

2. Research is much needed in this aspect of the roles of nursing service and healthcare service administrators in the retention of nurses in Ghana.

3. The research also revealed that parental influence greatly influenced the choice of nursing as a profession by their children. In view of this Nursing training schools/colleges should prepare interview guidelines such that it can explore the applicant's personality traits motives and psychomotor skills and affect during selection for enrollment into the training institutions. Industrial Psychologists should also be part of the interview panel during selection of nursing students. In this case students who are intrinsically motivated will be selected for the training.

4. The last significant finding of study indicated that there is a strong relationship between the intention to travel and the choice of nursing as a profession. The researchers therefore recommend the following:

- Nurse educators should educate student nurses about the essence of the nursing profession as a call to serve humanity but not for material gains such as the opportunity to travel abroad.

- The Government and the Ghana Health Service should formulate policies to develop and upgrade remunerations for professional nurses in the country.

- The Government of Ghana should formulate policies and guidelines for exporting professional nurses to the developed countries in exchange for foreign income. This will provide more resources for the training of more professional nurses in the country.

\section{Conclusion}

This study is aimed at finding the perception of student nurses about the nursing profession. It also sought to identify the role of parent in the choice of Nursing by their children as well as to investigate the relationship between the intention of student nurses to travel to developed countries after graduation and their choice of nursing as a profession.

In view of this three hypotheses were stated. The first finding was that student nurses had a high positive perception of the nursing profession. However, areas of poor perception included strained relationship between them and other members of the health team. Another major finding was that parents greatly influenced the choice of the profession by their children. The last significant finding of this study was that the students' choice of the profession positively correlated with their intention to travel abroad after graduation. Based on these findings, recommendations were made by the researchers as follows:

Firstly, the tutors in the nursing Training colleges and their students should make good use of the positive attitude observed translate this into practice for the patients to benefit. The poor relations between the students and the staff should be worked on by management. It was also recommended that industrial psychologists should be part of the interview panel when recruiting new students into the nursing profession. The last recommendation was for the tutors to educate students to understand that the nursing profession is a call to serve humanity rather than for material gains.

\section{References}

[1] Adam, E. (1991). To be a Nurse (2 ${ }^{\text {nd }}$ Ed), Canada, Montreal: W B Sounders.

[2] Adam, A., Bond, S. (2000). Hospital nurses job satisfaction, individual and organization characteristics. Journal of Advanced Nursing, 32(5):536-543.

[3] Beck, C.T. (2002). Experiences of choosing Nursing as a career. Journal of Nursing Education, 39(7):320-322.

[4] Benner, P.E., Tannor, C.A., Chesla, C.A. (2009). Expertise in nursing practice: Caring, clinical judgment and ethics. Second edition, Springer Publishing Company, New York.

[5] Bullough, V.L. \& Bullough, B. (1993). Medieval Nursing. Journal of Nursing History Review, 21(5):676-699.

[6] Corley, M.C. \& Mauksch, H.O. (1993). The nurse's multiple commitments. Journal of Professional Nursing, 9:116-122.

[7] Dolan, J.A., Fitzpatrick, M.L. \& Herrmann, E.K. (2005). Nursing in society: A historical perspective. Philadelphia: Saunders.

[8] Fry, S.T. \& Johnstone, M. (2008). Ethics in nursing practice: A guide to ethical decision making. ( $3^{\text {rd }}$ ed.). ICN, Stanford, England.

[9] Ghana Health Service. (2010). Annual report. Accra: Ghana Health Service, Government Printer.

[10] Gibbs, H. (2002). Count Your Blessings. Journal of Nursing Times, 98(26):29.

[11] Hawkins, R. (2001). Nursing Students career choice: A pilot study. Tenesse Nurse, 64(3):14-18.

[12] Kenny, C. (2002). Lack of training places revealed. Journal of Nursing Times, 98(43):1-5.

[13] Kersten. J. Bakewell, K. \& Meyer, D. (2003). Motivating factors in a Student's choice of nursing as a career. Journal of Nursing Education, 30 (1): 30-3

[14] Larsen, P.D., Mcgill, J. S. \& Palmer, S. J. (2003). Factors influencing career decisions: perspectives of Nursing Students in three types of programmes. Journal of Nursing Education, 42(4):168-173.

[15] Law, W. \& Arthur, D. (2003). Factors influencing Hong Kong School Students in their choice of a career in Nursing. International Journal of Nursing Studies, 40(1):23-32. 
[16] Milton, C.L. (2008). Accountability in nursing: Reflecting on ethical codes and professional standards of nursing practice from a Global perspective. Nursing Science Quarterly, 21:300-303.

[17] Ministry Of Health (2009). Human Resources Division. Annual report: Accra, Ghana.

[18] Oates, A. (2006). Nursing as a career choice, Department of health and human services, freedom of information Act. Journal of Nursing Education 20(9):1-34.
[19] Polit, D. F. \& Beck, C. T. (2008). Nursing research: Generating and assessing evidence for nursing practice. $8^{\text {th }}$ ed. Philadelphia: Lippincott William \& Wilkins.

[20] Stevens, K.A. \& Walker, E.A. (2003). Choosing a Career, Why not nursing for more High School Seniors. Journal of Nursing Education, 32(1):13-17.

[21] Wade, B. Degerhammer, M. (1995). The Development of a measure of job satisfaction for use in evaluating change in the system of care delivery. Scandinavian Journal of Caring Science, 5(4):195-201. 